\title{
LECTURE VIDEO RECORDINGS: PROS AN CONS. AN INVESTIGATION ON THEIR PERCEPTION AND UTILITY FROM THE POINTS OF VIEW OF BOTH STUDENTS AND TEACHERS
}

\author{
M. Ronchetti, H.K. Hwang \\ DISI - Università di Trento (ITALY)
}

\begin{abstract}
We report the results of an investigation regarding the acceptance of lecture video recording. It involved students of five cohorts. Our results are presented within the current literature state of art, and we discuss the pros of the video capturing practice as seen from the students, and the cons as perceived by the teacher.
\end{abstract}

Keywords: Video-lectures.

\section{INTRODUCTION}

Videos are gaining an ever-growing importance in the learning scenario. Educational movies have been used for more than half a century in schools, but after the millennium turn new ways to use of video technology have emerged. For the new generation, but also for many non-digital-natives, it is today normal and obvious to resort to social media, such as YouTube and Vimeo, for informal learning. This happens at anytime and anywhere, thanks to the diffusion of mobile devices such as the ubiquitous smartphones. On the other hand, short videos, typically of a maximum of 10 minutes, are an essential ingredient in most MOOCS, where they are interleaved with other activities. An additional, different type of usage of video as learning aid are video-recorded lectures, which have been here for approximately 20 years, even though their use has become relatively widespread only in the last decade. In this paper we deal this last form of video usage for learning purposes.

In particular, we present an investigation which spans over several years of lecture video-recording usage, reporting the point of view of students. We also discuss the difficulties of introducing this methodology and pros and cons also from the points of view of teachers. We also review what advantage and disadvantages are presented in literature, and compare them with our most recent results.

\section{PROBLEMS RELATED TO THE LECTURE VIDEO RECORDING PRACTICE}

Recording traditional lectures in the form of videos is a practice that dates back to the end of the nineties, and has been widely deployed in recent years (see [1,2] for a review). Since the very beginning, it has encountered the favor of students, as ascertained from very early studies [3] and confirmed by more recent ones (e.g. [4]).

Lecturers instead are often not favourable to this practice, for a variety of reasons, as discussed e.g. in the review paper by Witthaus and Robinson [5]. These include:

- Feeling uneasy about appearing in a video;

- Fear of being exposed to and judged by the colleagues;

- Fear that students might misuse the video, republishing portion of them on social media;

- Problems about the content of the lecture (e.g. confidentiality, sensitivity, expression of personal opinions);

- Concern on their own intellectual property and on the usage of copyrighted material;

- Lack of professional video quality;

- Deterrence of students' questions and interventions, because they could be intimidated by the recording of their comments;

- Recording lectures is "spoon-feeding" students, who should instead take notes; 
- Fear that attendance in class would drop;

- Feeling that video-recording would hinder the introduction of innovative teaching practices, such as those which put the learner at the center of the learning process.

The sum of these factors deters a wider usage of a practice, which as we mentioned is welcome and helpful for the students. Some of these obstacles are just myths or merely psychological issues.

For instance, in almost 20 years of practice, no case has been reported, as far as we know, about misusage of video by students or by colleagues.

Videos do not need to be "professional": they just need to be good enough for their goals. They are not part of the entertainment industry, and all that is needed is that the audio is clearly intelligible and that whatever appears in written form is readable.

Concerns about the content of the lectures (including intellectual properties issues) may be solved or at least softened by making videos visible only to authorized watchers (i.e. students of the course), e.g. with the help of a learning management system. Moreover, teachers could be in control of the recording process, e.g. pausing and resuming the registration process at their will, even though cutting out parts of the lecture could in part defeat the ultimate goal of the process. Moreover, they could at any time decide that a video should not be published, and have the possibility to edit them (even though this is a task, which requires time, competence and/or technical support).

Students note-taking activity could actually benefit from videos. In first place, as we shall discuss later when we will present our data, there is evidence that students use videos as an auxiliary tool to check and ameliorate their notes. Moreover, technical innovation coordinated with the lecture capture process could actually help students to take notes in a more efficient manner [6].

About the fact that the video-recording process could be an obstacle to innovative and more interactive practices, there are counterexamples such as e.g. the cases in which video-lectures are used for enabling flipped classroom practices (see e.g. [7]).

Attendance drop is probably the most frequent fear. It is a widely discussed issue in literature, For instance, Dickson et al. [8] report that students are not prone to use videos as a replacement of the presence in class. Moes and Young [9] confirm the finding. In a rather extensive study, Nordmann et al. [10] found no strong evidence that students who fail to attend the lecture are doing so because they are accessing the recording as a substitute. According to Billings and Gagliardi [11\} and to Dolnicar [12] attendance depends on a deliberate students' choice based on their benefit expectations, and Bassili [13] claims that students opt for being physically present at the lectures, when they expect the content to be difficult.

How can all these hindrances be overcome? Of course, one could try to convince teachers by reporting the evidence that is present in literature, but not necessarily such step would be effective. The elements, which can be decisive are two: emulation and organization. There is anecdotal evidence that when a number of ice-breaker start to video-capture their course, other will follow. It would be interesting to study what is the needed "nucleation" size: for sure one or two cases are not enough. In our experience, even repeated requests by students to extend to other courses the lecture capturing practice are not listened to, but we have evidence of a few cases, in which the "avalanche effect" has started.

If the "nucleation" is a bottom-up approach, by "organisation" we mean a top-down method. Some departments and universities have established policies, so that lecture capture becomes the norm, and not the exception. We think emulation will play a role also here, in the sense that if certain universities start delivering video-lectures as a standard service, it will be difficult for other ones in our competitive world to stay outside.

Laws could play a crucial role in all this. For instance, in U.K. the Disability Discrimination Act (1995) obliges educational institutions to take "reasonable adjustments" to avoid substantial disadvantage for disabled students (to see what are "reasonable adjustments" see e.g. the web site of the U.K. Equality and Human Rights Commission [13]). One way to comply with the Act is to allow students to autonomously record lectures (e.g. audio-recording), but a more complete response is to provide video recording of the lectures. Video-captured lectures help significantly at least certain type of disabilities: e.g. dyslexic students can in this way have more time to take notes. Such approach has been e.g. adopted by the University of Manchester, where as of 2017 only $18 \%$ of the lectures were not recorded (teachers have an "opt-out" option [14]). Other countries have established similar norms, or are about to. Also European Union directives are expected soon. 
We hence expect soon a big change in the acceptance by universities and teachers of the practice of lecture video recording.

\section{ADVANTAGES OF THE LECTURE VIDEO RECORDING: OUR RESULTS}

In the previous section we discussed the main obstacles to the acceptance of the lecture video recording practice. We now examine the advantages, as they emerge from an investigation we recently run.

We submitted a questionnaire to bachelor students of five cohorts (2014 to 2018), for a total of 554 students. During their first year, they had all been following a course on Object Oriented Programming for which lectures video-recording were provided. The lectures were recorded with a home-made recording tool, which has the advantage of being non-intrusive for the teacher, and presents an audio channel and two video channels: one containing a stream recorded with a wireless IP camera, and another one capturing whatever gets projected in the classroom. We believe providing the double channel is important, as demonstrated by an eye-tracking analysis of lecture capture environments [16]. That work showed that although the content was mostly provided through slides and voice, students glanced systematically at the image of lecturer in the video. The presence of a human figure seems to help students' concentration, and the non-verbal clues coming from the teacher's body language are an important ingredient.

The recorded videos were uploaded on a web site, and viewed with a standard browser. It was possible for students to change the size of the two videos at any time, making one of them larger or keeping both of them at the same size, to suite their cognitive needs Also, students could play the movie at various speeds, ranging from $1 / 2 x$ (half speed) to $2 x$ (e.g. for seeking one particular passage in the lecture). Videos lasted as long as the lectures themselves (in general 1,5 hours) and were typically published within a short time from the end of the recorded lecture (approximately 2 hours).

129 students responded to the survey (approximately $25 \%$ of 554 invited participants). $53 \%$ of the respondents belonged to the two most recent cohorts (2017 and 2018), and $22 \%$ to the two oldest cohorts (2014 and 2015), who already finished their bachelor. The answers they gave do not show any statistical dependence from the cohort.

The statistical uncertainty of the result we report has been evaluated in the simple random sampling assumption as $\sqrt{ }(p(1-p) / n)$ where $p$ is the percentage and $n$ is the sample size, and ranges between $1 \%$ (for $p=10 \%$ ) and $5 \%$ (for $p=50 \%$ ).

19 students (14.7\%) defined themselves "working students" (WS): for them it was generally impossible to follow the course participating to classes, and typically prepared the exams only with books and other material made available by the teachers (in the case of this course, also with the recorded videolectures).

At the beginning of the questionnaire, we asked if they felt the lecture video-recording was useful. The allowed answers were yes (1), no (0) or neutral (0.5). The overall average value was 0.97 , with 1.0 for WS and 0.96 for regular students (RS). The only non-positive answers came from a tiny number of $\mathrm{RS}$, with one "no" and 4 "neutral".

If the answer was yes, students were asked to explain, using free text, which were the main advantages. We then manually aggregated the responses. The main advantage (37.9\% of students), turns out to be the ability to recover lectures lost due to accidental facts (e.g. illness). Another $11.2 \%$ also quoted the lost lecture, but for a different reason: systematic causes, such as being a working student unable to follow the course due to time incompatibility. One student explicitly mentioned the ability of following lectures "anytime - anywhere". Another one mentioned the fact that the availability of the videos might encourage students not to come to class - a well know fear among teachers.

$26.7 \%$ of the students mentioned having used the video-lectures to systematically check the notes they took in class. One said that by knowing that the lecture itself was available later, he changed his attitude in class, giving more attention because he knew it was not necessary any more to frantically take notes to "grab" everything the teacher explained. Another one cited as a a great advantage the possibility of changing the speed of the video (making it faster to seek a particular point, or to skim well understood sections, or slower in critical points).

Other advantages mentioned by the participants were the possibility of using the videos to solve doubts, to review specific topics and to revise the course shortly before the exam. It is interesting to 
observe that while on the previous issues there was no significant difference between the answers of RS and WS, here the situation changes, as shown by the following Table 1.

Table 1. Patterns of usage of the video-lectures as spontaneously indicated by students.

\begin{tabular}{l|c|c|c}
\hline \hline & Overall & Working Students & Regular students \\
\hline Solve doubts & $13.8 \%$ & $5.6 \%$ & $15.3 \%$ \\
\hline Review specific topics & $34.5 \%$ & $11.1 \%$ & $38.8 \%$ \\
\hline revise the course before the exam & $19.0 \%$ & $11.1 \%$ & $20.4 \%$ \\
\hline \hline
\end{tabular}

We interpret this fact as a strong indication of a different attitude between the two subsets of students: while for WS the availability of recorded lecture is mainly a surrogate of the participation in class, for $\mathrm{RS}$ it becomes a complement to it. In both cases the availability of these resources is precious, but for very different reasons.

Later in the questionnaire we asked essentially the same question, proposing a non-exclusive multiple choice among the possible advantage we expected student to agree on: it turns out that the advantages we proposed in the multiple choice are more or less the same that students spontaneously indicated. It is important however to know that students saw the multiple-choice list only after having expressed their own thinking in the free text.

We proposed four options, as reported in the following Table 2.

Table 2. Patterns of usage of the video-lectures.

\begin{tabular}{l|c|c|c}
\hline \hline & Overall & Working Students & Regular students \\
\hline View lost lectures & $73.6 \%$ & $89.5 \%$ & $70.9 \%$ \\
\hline Clarify some doubts & $66.7 \%$ & $47.4 \%$ & $70.0 \%$ \\
\hline Review some portion of a lecture & $69.8 \%$ & $52.6 \%$ & $72.7 \%$ \\
\hline Check one own's notes & $29.5 \%$ & $26.3 \%$ & $30.0 \%$ \\
\hline \hline
\end{tabular}

The percentages are different from the ones reported in Table 1: this is due to the different way of posing the question. The answers in Table 1 are relative to what students mentioned without any suggestion, Table 2 reports how much they recognize their own behaviour in the proposed answers.

Again, we can notice a difference between the responses of the two subsets of students, which confirms our previous observation.

The low percentage of checking notes derives probably from the fact that many students do not take notes at all, relying on the copy of the slides which are available from the course web site.

On the delicate point regarding the danger of lowering the presence in class if video-recorded lectures are provided, on a scale from 0 (does not encourage absence) to 1 (encourages absence) we had a result of 0.18 , which corresponds to percentages of $10.8 \%$ for those who believe absence would grow, $73.6 \%$ for the ones believing in the opposite thesis, with a $15.5 \%$ of "no opinion".

We tried to understand how effective are the video-lecture in letting students feel they are able to study better, and to obtain better results at the exam. Students responded on a five values Lickert scale. The results, normalized on the range 0 to 1 , yielded respectively 0.75 and $0.69(0.83$ and 0.76 for WS, 0.74 and 0.68 for RS). WS hence find a bigger advantage that RS, but also for RS the availability of such resources are of great help.

We collected information about the frequency with which students used the recorded lectures, ranging from 0 (Never) to 1 (Almost for every lecture), with two intermediate values (0.33 - Rarely, 0.67 Rather often). The average value of the responses was 0.58 ( 0.63 for WS, 0.57 for RS). The distribution was: Never $1.5 \%$, Rarely $40.3 \%$, Often $41.0 \%$, Almost always $17 \%$.

To be able to attempt to correlate the perception and acceptance of the videos with other parameters, we also collected other data: 
- the final scores. According to the Italian system, votes are on a scale ranging from 18 (sufficient) to 31 (cum laude). The average for the course was 26.5, with no difference between RS and WS.

- the number of attempts, which were necessary to pass the exam (in Italy it is possible to fail an exam an indefinite number of time, and to retry it over and over): average for the course was 1.73 (1.9 for WS, 1.7 for RS);

- novelty of the presented material: some students already know the programming language taught in the course (Java) and/or are already familiar with the concepts of Object-Oriented Programming, while others don't. On a scale 0 to 1, where 0 means "I did not know anything" and 1 means "I knew already everything", the average was 0.42 ( 0.36 for WS and 0.43 for RS).

We tried to establish if there was any correlation between how much students used video-lectures and the final scores. We actually found none: over the whole set of data, the correlation factor $\mathrm{R}$ is 0.16 .

Checking the various pairs of variables, the only ones which show some degree of correlation are

- final score vs. previous knowledge (novelty of the presented material), $R=0.33$;

- frequency of usage vs feeling of a better study thanks to videos, $R=0.39$;

- frequency of usage vs feeling of a better performance at the exam thanks to videos, $R=0.47$;

- feeling of better study vs feeling of better performance at the exam thanks to videos, $R=0.75$.

All other pairs show $\mathrm{R}$ less o equal to 0.22 .

However, if we exclude WS (who used video as a replacement of the presence in class) and look at the average scores grouping students by frequency, we obtain the results reported in the following Table 3, where $\mathrm{N}$ indicates the numerosity of the group. In the table "Familiarity with the course topic" is relative to the (self-assessed) novelty of the presented material. As mentioned above, it ranges from 0 to 1 ( $0=$ student knew nothing before the course, $1=$ student believes he already knew everything).

Table 3. Average score and familiarity (regular students only), grouped by frequency of video usage.

\begin{tabular}{l|c|c|c|c}
\hline \hline \multicolumn{1}{c|}{ Frequency: } & $\begin{array}{c}0-N e v e r \\
(N=2)\end{array}$ & $\begin{array}{c}0.33-\text { Rarely } \\
(N=46)\end{array}$ & $\begin{array}{c}0.67-\text { Often } \\
(N=44)\end{array}$ & $\begin{array}{c}\text { 1-Almost Always } \\
(N=18)\end{array}$ \\
\hline Average score & 29.0 & 27.09 & 26.2 & 25.22 \\
\hline Familiarity with the course topic & 0.75 & 0.50 & 0.40 & 0.32 \\
\hline
\end{tabular}

At a first sight, the score data seem to suggest that the more students used videos, the worse was their performance! On the other hand, a different interpretation is that only the students with some degree of difficulty use videos, and one could argue that without videos their performance would have been even lower. The second interpretation is supported by the values of the familiarity with the topic: the very small group of students who never used the videos, believe they knew most of the course material. In fact they got a very high average score. However, not only they felt no need to use the videos, but also did not study much (in fact their average score does not saturate).

In Table 4 the aggregation is performed by Familiarity with the course content.

Table 4. Average score and frequency of video usage (regular students only), grouped by familiarity.

\begin{tabular}{l|c|c|c|c|c}
\hline $\begin{array}{c}\text { Familiarity with } \\
\text { the course topics }\end{array}$ & $\begin{array}{c}1-\text { knew everything } \\
(\mathbf{N}=17)\end{array}$ & $\begin{array}{c}0,75 \\
(\mathbf{N}=19)\end{array}$ & $\begin{array}{c}0,50 \\
(\mathbf{N}-20)\end{array}$ & $\begin{array}{c}\mathbf{0 , 2 5} \\
(\mathbf{N}=25)\end{array}$ & $\begin{array}{c}0 \text { - knew nothing } \\
(\boldsymbol{N}=29)\end{array}$ \\
\hline Average score & 29,1 & 26,8 & 26,6 & 26,5 & 24,6 \\
\hline Frequency & 0,47 & 0,54 & 0,58 & 0,56 & 0,64 \\
\hline \hline
\end{tabular}

Also here, data show that students with a strong previous knowledge used less, on the average, the videos, but they do not get (on average) the full score. Students who did not know anything beforehand are disadvantaged in the final score, and are the group who used the most the videos. This seems to confirm that videos are most valuable for the weakest students, as one would expect. 
In Table 5 we select only the top RS (i.e. those who got the full score -30 or 30 cum laude) to show that they are rather evenly distributed across groups of previous knowledge.

Table 5. Average frequency of video usage (only for top students) grouped by familiarity.

\begin{tabular}{c|c|c|c|c|c}
\hline \hline $\begin{array}{c}\text { Familiarity with } \\
\text { the course topic }\end{array}$ & $\begin{array}{c}1-\text { knew everything } \\
(N=9)\end{array}$ & $\begin{array}{c}0.75 \\
(N=4)\end{array}$ & $\begin{array}{c}0.50 \\
(N-6)\end{array}$ & $\begin{array}{c}0.25 \\
(N=8)\end{array}$ & $\begin{array}{c}0-\text { knew nothing } \\
(N=4)\end{array}$ \\
\hline Frequency & 0.44 & 0.67 & 0.44 & 0.54 & 0.67 \\
\hline \hline
\end{tabular}

Finally, we mention the last question we posed: would students like other courses to video-recorded? The plebiscitary answer was "Yes", with a $98.5 \%$ vs a $1.5 \%$ of undecided, and no "No".

\section{CONCLUSIONS}

Our results are mostly in-line with the existing literature on this topic. Some aspects are however slightly different.

In first place, many studies claim that students use video-lectures as supplementary material, and not as a replacement (e.g. [8], [17-20]). In our work we distinguish between working students (WS) and regular student (RS), and we find that the two groups are characterised by a usage difference: videolectures are essentially viewed as a replacement for the presence in class by WS, while RS tend to use them mostly as supplementary material.

We investigated the behaviour of students, trying to correlate their frequency of usage of recorded video lectures with other parameters, such as previous knowledge and proficiency. We found a clear correlation between previous knowledge and video usage: on average, the less students feel to know, the more they tend to use videos. However if we restrict to students who obtained the best marks at the exam at the top, such correlation is not so clear any more: even students who had a good previous knowledge used videos In a significant way. In this case however the numbers on which statistics is based are small.

Relating proficiency with frequency of video usage is a controversial matter in literature. For instance, Traphagen et al. [21] claim that the more a student had viewed the recordings, the better they performed at the end of the course, while Witthaus and Robinson in their review paper [5] summarize research ranging from positive to negative effects.

In our case, by grouping students by frequency of video usage (Table 3), we find an apparent negative correlation: the more students watched the videos, the lowest their final score! However, we can bring in the other factor, i.e .the previous knowledge. The causal relations seem therefore to be dual:

- The less students knew before the course, the more they watched videos;

- The less students knew before the course, the lower was their final score.

At the same time, we reported that there is a clear relation between frequency of usage of the videos and students' feeling of having studied better, and to be better prepared for the exam.

Hence, we can conclude that although the more (on average) students watched videos, the lower their final score, such relation is not causal, but mediated by the previous knowledge, and probably the scores would have been even lower if videos had not been available.

Our results may be peculiar for the course which was video-recorded. Object-Oriented Programming has a number of theoretical issues, but the exam is also project-based, and requires to have introjected a good deal of competence, which derives from extensive practical exercise. Acquiring it requires time, and for this reason probably the previous knowledge turns out to be so important.

Courses in other domains might behave differently.

\section{REFERENCES}

[1] Ronchetti, M. "Video-Lectures over Internet: The Impact on Education" in E- Infrastructures and Technologies for Lifelong Learning: Next Generation Environments, New York/USA: IGI Global, pp. 253-270, 2011 
[2] Ronchetti, M. "Perspectives of the Application of Video Streaming to Education" in Streaming Media Architectures, Techniques, and Applications: Recent Advances, Hershey PA, USA: Information Science Reference, IGI Global, pp. 411-428, 2011

[3] Ronchetti M. "Has the time come for using video-based lectures over the Internet? A Test-case report". Proceedings of the IASTED International Conference "Computers and Advanced Technology in Education 2003", Rhodes (Greece), June 30 - July 2, p. 305, 2003

[4] Pilarski, P. P., Alan Johnstone, D., Pettepher, C. C., \& Osheroff, N. "From music to macromolecules: Using rich media/podcast lecture recordings to enhance the preclinical educational experience". Medical Teacher, 30(6), pp. 630-632, 2008

[5] Witthaus, G.R. and Robinson, C.L. "Lecture capture literature review: A review of the literature from 2012-2015". Loughborough: Centre for Academic Practice, Loughborough University. (2015)

[6] Ronchetti M., Lattisi T., "Grab that Screen! Architecture of a System that Changes the Lecture Recording and the Note Taking Processes". In: Gennari R. et al. (eds) Methodologies and Intelligent Systems for Technology Enhanced Learning, 9th International Conference. MIS4TEL 2019. Advances in Intelligent Systems and Computing, vol 1007, pp 113-120, 2020

[7] Ronchetti, M., "Using video lectures to make teaching more interactive" International Journal of Emerging Technologies in Learning (IJET), June 2010.

[8] Dickson, P. E., Warshow, D. I., Goebel, A. C., Roache, C. C., \& Adrion, W. R. "Student reactions to classroom lecture capture". Proceedings of the 17th ACM Annual Conference on Innovation and Technology in Computer Science Education - ITiCSE '12, pp.144-149 (2012).

[9] Moes, S. \& Young, C., "Which types of lecture capture knowledge and instruction clips could improve the quality of learning outcomes?" In ICERI 2013. Seville: International Conference of Education, Research and Innovation (ICERI), 2013.

[10] Nordmann, E., Calder, C., Bishop, P. et al." Turn up, tune in, don't drop out: the relationship between lecture attendance, use of lecture recordings, and achievement at different levels of study“" High Educ. (2019) 77: 1065 (2019). https://doi.org/10.1007/s10734-018-0320-8

[11] Billings-Gagliardi, S., \& Mazor, K. M. (2007). Medical Student Attendance at Non-compulsory Lectures: Do Electronic Course Materials Matter? Advances in Health Sciences Education, 12(2), 201-210.

[12] Dolnicar, S. (2005). Should We Still Lecture or Just Post Examination Questions on the Web?: The Nature of the Shift Towards Pragmatism in Undergraduate Lecture Attendance. Quality in Higher Education, 11(2), 103-115.

[13] Bassili, J. N. (2008). Media Richness and Social Norms in the Choice to Attend Lectures or to Watch them Online. Journal of Educational Multimedia and Hypermedia, 17(4), 453-475.

[14] Web site of the U.K. Equality and Human Rights Commission, https://www.equalityhumanrights.com/en/advice-and-guidance/what-are-reasonable-adjustments, last visited Sept.25, 2019

[15] https://accessibility.jiscinvolve.org/wp/2017/05/18/lecture-capture/, last visited Sept.25, 2019

[16] Kukkonen, I.K. "Students' perceptions and perceived value of lecture capture in teacher education", Diverse Conference, Leuven, Belgium, 2012

[17] Karnad, A., "Student use of recorded lectures: a report reviewing recent research into the use of lecture capture technology in higher education, and its impact on teaching methods and attendance". London: LSE 2013

[18] Marchand, J.-P., Pearson, M.L. \& Albon, S.P., "Student and faculty member perspectives on lecture capture in pharmacy education". American Journal of Pharmaceutical Education, 78(4), p.74, 2014.

[19] Saunders, F.C. \& Hutt, I. "Enhancing large-class teaching: a systematic comparison of rich-media materials". Higher Education Research \& Development, pp.1-18, 2014

[20] Wiese, C. \& Newton, G." Use of Lecture Capture in Undergraduate Biological Science Education". Canadian Journal for the Scholarship of Teaching and Learning, 4(2)., 2013 
[21] Traphagen, T., Kucsera, J. V., \& Kishi, K. "Impact of class lecture webcasting on attendance and learning". Educational Technology Research and Development, 58(1), 19-37, 2010 